\title{
Urban Chagas disease in children and women in primary care centres in Buenos Aires, Argentina
}

\author{
Guillermo Moscatelli ${ }^{1 /}{ }^{+}$, Ada Berenstein ${ }^{2}$, Ana Tarlovsky ${ }^{3}$, Susana Siniawski², Miguel Biancardi ${ }^{1}$, \\ Griselda Ballering ${ }^{1}$, Samanta Moroni', Marta Schwarcz ${ }^{4}$, Susana Hernández ${ }^{4}$, \\ Facundo García-Bournissen ${ }^{1}$, Andrés Espejo Cozzi ${ }^{4}$, Héctor Freilij', Jaime Altcheh ${ }^{1}$
}

\footnotetext{
${ }^{1}$ Ricardo Gutiérrez Children's Hospital, Department of Parasitology and Chagas, Buenos Aires, Argentina ${ }^{2}$ Primary Care Centre, Community Action Centre 15, Buenos Aires, Argentina ${ }^{3}$ Primary Care Centre, Community Action Centre 11, Buenos Aires, Argentina ${ }^{4}$ Interamerican Open University, Centre of Studies on Human Science and Health, Buenos Aires, Argentina
}

The primary objective of this study was to estimate the prevalence of this disease in women of childbearing age and children treated at health centres in underserviced areas of the city of Buenos Aires. Demographic and Chagas disease status data were collected. Samples for Chagas disease serology were obtained on filter paper and the reactive results were confirmed with conventional samples. A total of 1,786 subjects were screened and 73 positive screening results were obtained: 17 were from children and 56 were from women. The Trypanosoma cruzi infection risk was greater in those individuals who had relatives with Chagas disease, who remember seeing kissing bugs, who were of Bolivian nationality or were born in the Argentine province of Santiago del Estero. The overall prevalence of Chagas disease was 4.08\%. Due to migration, Chagas disease is currently predominantly urban. The observed prevalence requires health programme activities that are aimed at urban children and their mothers. Most children were infected congenitally, which reinforces the need for Chagas disease screening of all pregnant women and their babies in Argentina. The active search for new cases is important because the appropriate treatment in children has a high cure rate.

Key words: Trypanosoma cruzi - Chagas disease - congenital transmission - prevalence - epidemiology - treatment

The epidemiological profile of Chagas disease has changed. Currently, vector transmission is partially controlled in many Southern Cone countries (Segura et al. 1999). In Argentina, the provinces of Jujuy, La Pampa, Rio Negro, Neuquén, Entre Ríos, Santa Fe and San Luis and Misiones have controlled domestic vector transmission (MSAL 2014). At present, most of the new cases occur in urban areas through congenital transmission (Altcheh 2010). However, few studies have reported this information (Luluaga \& Lazzari 2002).

According to the 2010 Argentine census data, 53.3\% of Argentina's population lives in the city of Buenos Aires and in the province of Buenos Aires, which explains why the largest number of infected cases resides in this area. The city of Buenos Aires is also the focus of a significant migratory flow from countries with high infection rates, such as Bolivia, Paraguay and Peru (INDEC 2010). No vectorial transmission is present in the city of Buenos Aires.

Primary Health Care and Community Action Centres (CESACs) are part of the structure of the Primary Health Care of city of Buenos Aires and are composed of multidisciplinary teams that serve primarily low-income

doi: 10.1590/0074-02760150107

Financial support: Foundation Bunge \& Born, AJ Roemmers Foundation, Ricardo Gutiérrez Children's Hospital

+Corresponding author: gfmoscatelli@yahoo.com.ar Received 17 March 2015

Accepted 3 July 2015 populations, which include a large number of migrants from the north of Argentina and neighbouring countries. This population profile suggests a high probability of discovering Trypanosoma cruzi-infected women and potential sources of new congenital cases.

The primary objective of this study was to estimate the prevalence of Chagas disease in women of childbearing age and children seen at CESAC in underserviced areas of the city of Buenos Aires.

\section{SUBJECTS, MATERIALS AND METHODS}

Between June 2005-April 2007, a multicentre crosssectional prevalence study was performed in CESAC 11 (Balvanera neighbourhood) and CESAC 15 (San Telmo neighbourhood) and, from December 2006-December 2009, in CESAC Los Piletones (Villa Soldati neighbourhood). The target population of these centres included approximately 170,000 people in CESAC $11,55,000$ people in CESAC 15 and 4,000 in Los Piletones.

Inclusion criteria - Children $>1$ year old and women aged 21-40 years old. Convenience sampling was conducted from groups who attended the CESACs for healthy child visits. All of the patients were asked to sign a written informed consent form.

Exclusion criteria - Subjects who were not residents in the catchment area of the CESAC (i.e., did not reside in the city of Buenos Aires) and parents who did not understand the nature, purpose and possible consequences of the study.

The subjects were enrolled in the study using the following strategy: an informative workshop on Chagas disease 
was performed weekly in waiting rooms in the CESACs and the study protocol was explained at that moment. The target population was invited to participate. Demographic data were collected, including the enrolled patient's age, origin, place of birth, travel history and family structure.

Diagnostic studies and treatment - Diagnostic criteria - The subjects were considered infected with Chagas disease when two serological techniques for filter paper were reactive.

Validation of the dry blood spot serological method (Zicker et al. 1990, Palacios et al. 2000) - Blood samples for serological screening were obtained on filter paper (Schleicher \& Schuell ${ }^{\circledR}$ no. 903 and 595). From each subject, six drops of blood were obtained via finger prick. At the time of analysis, $2.8 \mathrm{~cm}^{2}$ of the paper was eluted with $125 \mu \mathrm{L}$ of saline for $12 \mathrm{~h}$ at $4^{\circ} \mathrm{C}$ (Altcheh 2010). The eluates were analysed with indirect haemagglutination (IHA) (Polychaco Lab, Argentina) and ELISA tests (Wiener Lab, Argentina). Briefly, samples from 75 subjects from the Department of Parasitology and Chagas, Buenos Aires Children's Hospital were analysed using conventional serology and dry blood spot methods. Fifty-six samples were from patients with $T$. cruzi infection confirmed via conventional serology testing and 19 samples were from noninfected patients. Based on the validation results and from previously published data on the method (Zicker et al. 1990, Palacios et al. 2000), the following cut off values were chosen for screening with the filter paper method: IHA $\geq 1 / 8$ dilutions, ELISA $R \geq 0.8(\mathrm{R}=$ optic density of the simple/optic density of the negative control).

Comparison of the dry blood spot technique vs. traditional techniques showed a sensitivity of $96.6 \%$ [95\% confidence interval (CI) 87.7-99.6], a specificity of 73.7\% (95\% CI 48.8-90.9), a positive predictive value of $91.5 \%$ (95\% CI 81.3-97.2) and a negative predictive value of $87.5 \%$ (95\% CI 61.7-98.5). Additionally, the likelihood ratio was 3.664 .

A congenital infection was considered in individuals born from infected mothers with $T$. cruzi infection who had two reactive serological tests and had not received transfusions nor travelled to an endemic area.
In children and women who were infected, a study of the family was requested. Infected children were treated with 5-8 $\mathrm{mg}$ benznidazole (BZ)/ $\mathrm{kg} / \mathrm{day}$ in two doses for 60 days. Infected adult patients were referred to adult parasitology centres for further evaluation and treatment.

Statistical analysis - The clinical, epidemiological and serological data were recorded and analysed using Epi Info 6.04 - CDC. To estimate the Chagas disease prevalence, the proportion of children and women who had two positive serological techniques was calculated. We compared the proportion of cases for each qualitative variable using a chi square test and Student's $t$ test was utilised for continuous variables.

Univariate regression analyses were performed to establish the relationship between positive serological and explanatory variables.

Sample size calculation - Considering an estimated prevalence of $2.5 \%$ with an error of $30 \%$ and a $95 \%$ CI, 1,500 subjects were required, considering a $20 \%$ rejection.

Ethics - The Ethical and Research Review Boards of the Ricardo Gutierrez Children's Hospital approved the study. Written informed consent was required from the patients' legal representatives, as well as assent from the patients as appropriate.

\section{RESULTS}

Population - A total of 1,786 subjects were included in the study. The mean age was 19.2 years (range 1-40 years), $73 \%$ were under 20 years of age and $68.6 \%$ were female. More than half of the subjects (58.7\%) were of Argentine origin, followed by natives of Bolivia, Peru and Paraguay (Table I). All of the patients resided in the city of Buenos Aires. Only $56.1 \%$ of the subjects had a history of travel to endemic areas of Argentina or neighbouring countries. The endemic areas that were visited included Argentina (50.1\%), Bolivia (21.7\%), Paraguay (15.6\%), Peru $(9.5 \%)$, Brazil $(<2 \%)$, Uruguay $(<2 \%)$ and Chile $(<$ $2 \%$ ). Twenty-six per cent of patients reported having seen kissing bugs and $6.4 \%$ had received transfusions.

TABLE I

Hometown of children and women in the study

\begin{tabular}{|c|c|c|c|c|}
\hline Country & $\begin{array}{c}\text { CESAC } 11 \\
(\mathrm{n}=380) \\
\mathrm{n}\end{array}$ & $\begin{array}{c}\text { CESAC } 15 \\
(\mathrm{n}=608) \\
\mathrm{n}\end{array}$ & $\begin{array}{l}\text { Los Piletones } \\
\qquad(\mathrm{n}=798) \\
\mathrm{n}\end{array}$ & $\begin{array}{c}\text { Total } \\
(\mathrm{n}=1,786) \\
\mathrm{n}(\%)\end{array}$ \\
\hline Argentina & 239 & 449 & 361 & $1,049(58.7)$ \\
\hline Bolivia & 13 & 9 & 282 & 304 (17) \\
\hline Peru & 102 & 95 & 25 & $222(12.4)$ \\
\hline Paraguay & 18 & 44 & 122 & 184 (10) \\
\hline Uruguay & 4 & 9 & 1 & $14(0.8)$ \\
\hline Brazil & 1 & - & 6 & $7(0.4)$ \\
\hline Chile & 2 & 1 & - & $3(0.2)$ \\
\hline Otros & 1 & 1 & 1 & $3(0.2)$ \\
\hline
\end{tabular}

CESAC: Community Action Centre. 
Twenty per cent had relatives with Chagas disease and this percentage increased to $49.3 \%$ in infected patients. A total of $82.9 \%$ of the subjects' mothers lived in northern Argentina or neighbouring countries; in infected subjects this percentage rose to $94.5 \%$.

Results of the Chagas serology testing - Study results on filter paper - A total of 1,786 blood samples were collected for screening (on filter paper): 380 from CESAC 11, 608 from CESAC 15 and 798 from CESAC Los Piletones.

Screening was reactive in 73 subjects $(4.1 \%)$. According to the age groups, we observed that the higher the age, the higher the prevalence (Table II)

Data from infected children and women - Of the 73 reactive subjects, 17 were children and 56 were women (Fig. 1) Their average age was 27.7 years (interquartile range 24.5-30.8).

The infected patients were from Bolivia (42.5\%), Argentina (41.1\%) and Paraguay (16.4\%). The patients from Argentina were from Buenos Aires (33.3\%), Santiago del Estero (13.3\%) and Salta (13.3\%). The majority $(76.7 \%)$ had a history of travel to endemic areas (Bolivia $48.9 \%$, Argentina $36.2 \%$ and Paraguay $14.9 \%$ ), with $61.7 \%$ visiting rural areas. Half of the patients recalled seeing the vector (kissing bugs) and 9.5\% had received transfusions. Approximately half of the patients (51.4\%) reported having relatives with Chagas disease.

The following factors were associated with a greater risk of $T$. cruzi infection: having a relative with Chagas, having seen kissing bugs or being born in Santiago del Estero (Argentina) (Table III).

Study of the family group - We studied 18 individuals from eight families with positive cases; as a result, we identified six new positive cases (Fig. 1). Two cases were children (4 and 10 years old) who were born in Buenos Aires to mothers with Chagas disease who had not received transfusions or travelled to endemic areas. Therefore, we assume that the route of infection was congenital in both cases.

Treatment - All of the reactive children were recalled and a second blood sample was obtained via venipuncture to confirm the infection (Fig. 2) These

TABLE II

Prevalence by fractions ranges ${ }^{a}$

\begin{tabular}{lcc}
\hline $\begin{array}{l}\text { Age } \\
\text { (years) }\end{array}$ & Reactive & $\mathrm{n}(\%)$ \\
\hline $0-5$ & 2 & $553(0.36)$ \\
$6-10$ & 3 & $182(1.64)$ \\
$11-15$ & 5 & $95(5.26)$ \\
$16-20$ & 5 & $112(4.46)$ \\
$21-30$ & 38 & $377(10.08)$ \\
$31-40$ & 20 & $467(4.28)$ \\
Total & 73 & $1,786(4.08)$ \\
\hline
\end{tabular}

$a$ : children and women included.

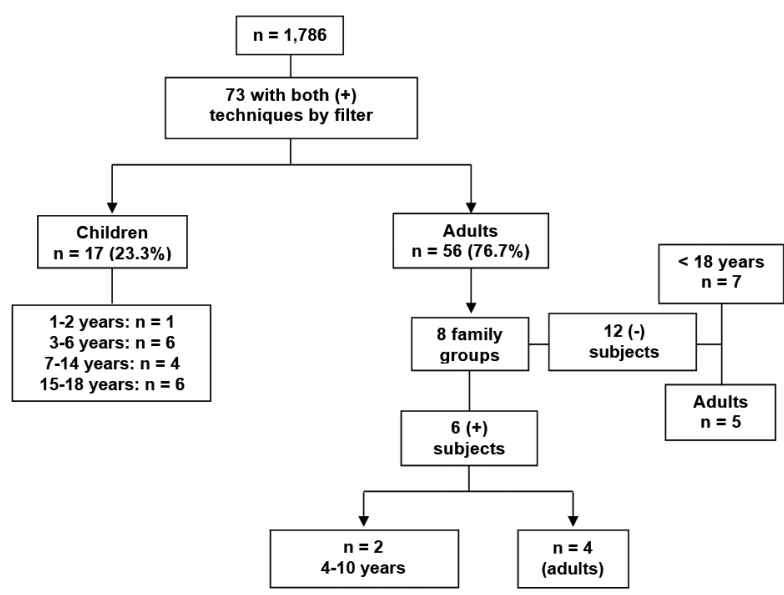

Fig. 1: patients with both positive techniques by filter paper.

samples were considered reactive when the IHA titres were $\geq 1 / 16$ and the ELISA $R \geq 1.2$.

Five- $8 \mathrm{mg}$ BZ/kg/day was prescribed. All completed 60 days with good tolerance, presenting a steady decrease or disappearance of specific T. cruzi antibodies.

The infected adults were referred for follow-ups to hospitals in the area of the CESACs.

\section{DISCUSSION}

To develop and implement effective interventions to control Chagas disease transmission and establish an effective surveillance system, particularly in paediatric patients, it is necessary to broaden the knowledge regarding the $T$. cruzi epidemiology and infection risk factors.

Migratory phenomena have generated a major change in the epidemiological Chagas disease profile (Moscatelli et al. 2013). According to the 2010 Argentine census, 550,713 Paraguayans, 345,272 Bolivians and 157,514 Peruvians live in Argentina. Compared with the 2001 census, there was a marked increase in the arrival of immigrants from Bolivia, Paraguay and Peru to city of Buenos Aires and the greater Buenos Aires area.

The largest increase in the number of foreign immigrants in city of Buenos Aires since 2001 was observed in the Flores, Lugano and Retiro neighbourhoods. These neighbourhoods coincide with the areas covered by the centres participating in the study (INDEC 2010).

We observed that $41.3 \%$ of the subjects in the study were immigrants, mostly from Bolivia, Paraguay and Peru. This phenomenon was also observed in nonendemic countries, such as Australia, Canada, Spain and the United States of America (Schmunis 2007).

Most of our study subjects were female adolescents, which coincided with the 2010 census data that showed a high proportion of young women amongst the reported immigrants. The high birth rate of the population helps explain the congenital case increase in our country in recent years. It was estimated that between 1,000-1,300 infected children are born in Argentina every year (MSAL 2010). 
TABLE III

Risk factors for infection with Trypanosoma cruzi in the subjects studied

\begin{tabular}{|c|c|c|c|c|c|}
\hline & & $\begin{array}{l}\text { Risk factors }+ \\
\text { /infected } \\
\text { (n) }\end{array}$ & $\begin{array}{l}\text { Risk factors }+ \\
\text { /not infected } \\
\text { (n) }\end{array}$ & $\begin{array}{l}\text { Odds ratio } \\
\text { (CI 95\%) }\end{array}$ & $\mathrm{p}$ \\
\hline \multicolumn{2}{|l|}{ Female sex } & $58 / 73$ & $1,236 / 1,713$ & $1.5(0.8-2.6)$ & 0.1836 \\
\hline \multicolumn{2}{|l|}{ Travel to endemic area } & $55 / 71$ & $931 / 1,688$ & $2.8(1.5-4.9)$ & 0.0002 \\
\hline \multicolumn{2}{|l|}{ Travel to rural area } & $28 / 47$ & $480 / 853$ & $1.1(0.6-2)$ & 0.7629 \\
\hline \multicolumn{2}{|l|}{ Seeing kissing bugs } & $37 / 73$ & $300 / 1,698$ & $4.8(2.9-7.7)$ & $<0.0001$ \\
\hline \multicolumn{2}{|l|}{ Received transfusions } & $7 / 73$ & $107 / 1,703$ & $1.6(0.7-3.5)$ & 0.2277 \\
\hline \multicolumn{2}{|l|}{ Familiar with Chagas } & $36 / 73$ & $265 / 1,700$ & $5.2(3.2-8.4)$ & $<0.0001$ \\
\hline \multicolumn{2}{|c|}{ Born from a mother who travel to endemic zone } & $69 / 73$ & $1,402 / 1,702$ & $3.7(1.3-10.1)$ & 0.0041 \\
\hline \multirow[t]{3}{*}{ Nationality vs. others } & Argentina & $31 / 73$ & $1,027 / 1,708$ & $0.5(0.3-0.7)$ & 0.0033 \\
\hline & Bolivia & $30 / 73$ & $297 / 1,708$ & $1.6(0.9-2.6)$ & 0.0661 \\
\hline & Paraguay & $12 / 73$ & $167 / 1,708$ & $1.8(0.9-3.4)$ & 0.0726 \\
\hline \multicolumn{2}{|c|}{ Argentine-born in Santiago del Estero vs. other provinces } & $5 / 31$ & $46 / 1,049$ & $4.2(1.5-11.4)$ & $<0.01$ \\
\hline
\end{tabular}

CI: confidence interval.

The majority of the infected individuals who were identified in our study were of Bolivian nationality. In Argentina, the provinces with the highest Chagas disease prevalence were the northern provinces of Chaco, Santiago del Estero, Formosa, La Rioja, Salta and Jujuy (MSAL 2014) and this was reflected in our study population.

There are few studies that evaluated the T. cruzi infection prevalence in city of Buenos Aires, in which the estimated number of births was 44,796 and $1.71 \%$ were from $T$. cruzi infected pregnant women (Spillmann et al. 2013). Almost half (41\%) of these women were from Argentina (most were originally born in the Chaco and Santiago del Estero provinces), 29\% were from Bolivia, $18 \%$ were from Peru and 9\% were from Paraguay.

In our study, we found a $4.08 \%$ Chagas disease prevalence, which included the following risk factors: being a relative in a family with Chagas, having seen kissing bugs or being born in Santiago del Estero (Argentina). We observed a higher prevalence in children than what was reported in a 2002 survey of healthy school children in city of Buenos Aires that showed a prevalence of

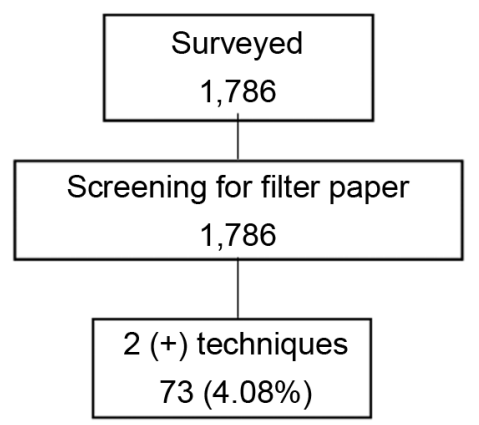

Fig. 2: population surveyed.
$0.36 \%$ (Luluaga \& Lazzari 2002). The almost five-fold difference in the observed prevalence in our study can be explained by the characteristics of the enrolled populations, with a high percentage of the migrant population being from endemic areas in our study.

The high prevalence found in our study could be biased because it was conducted in an area of the city with a large component of a migrant population that was from endemic areas.

This study led to the diagnosis of seven congenitally infected children, five from the initial cohort and two from the active screening within family groups of positive subjects for both techniques on filter paper. All of the children infected that were treated with BZ had good tolerance and responses. This showed that it is important to diagnose and treat children with Chagas disease to prevent the development of cardiac complications and new congenital cases.

Given that treating children with BZ or nifurtimox has high cure rates with low adverse events, unlike these treatments in adults (Altcheh et al. 2011), it should be a public health priority to screen for Chagas disease in pregnant women for further study and treatment of their children if they are infected (Altcheh et al. 2011).

Finally, the (albeit limited) presence of uninfected vectors in some areas of the city of Buenos Aires highlights the importance of continuous surveillance and elimination efforts to prevent infection of the vectors from infected patients and potential reintroduction of vectorial transmission.

Due to migration, as evidenced in this study, Chagas disease has become a predominantly urban disease. The observed infected subject prevalence rate requires health activities that are aimed at this group of patients.

An infected individual that is undiagnosed into adulthood may become a blood donor or, in the case of women, generate new potential cases by transplacental trans- 
mission, which may thus help perpetuate the endemic. In migration cases, the disease may spread to other regions as with the mothers of the subjects who were studied.

Progress in the control of vector-borne and blood in blood banks reinforces the need to implement active search programmes for the detection of pregnant women and children with Chagas disease.

\section{REFERENCES}

Altcheh J 2010. La enfermedad de Chagas a 100 años de su descubrimiento. Arch Argent Pediatr 108: 4-5.

Altcheh J, Moscatelli G, Moroni S, García-Bournissen F, Freilij H 2011. Adverse events after the use of benznidazole in infants and children with Chagas disease. Pediatrics 127: e212-e218.

INDEC - Instituto Nacional de Estadística y Censos 2010. Censo nacional de población, hogares y viviendas, Argentina, 2010. Available from: censo2010.indec.gov.ar/.

Luluaga I, Lazzari J 2002. Prevalencia de la enfermedad de Chagas en escolares de la ciudad de Buenos Aires. Rev Argen Cardiol 70: $364-368$.

Moscatelli G, García-Bournissen F, Freilij H, Berenstein A, Tarlovsky A, Moroni S, Ballering G, Biancardi M, Siniawski S, Schwarrcz M, Hernández S, Cozzi AE, Altcheh J 2013. Impact of migration on the occurrence of new cases of Chagas disease in Buenos Aires city, Argentina. J Infect Dev Ctries 157: 635-637.
MSAL - Ministerio de Salud de la Nación Argentina. 2010. Boletín epidemiológico anual 2010. Available from: msal.gov.ar/saladesituacion/boletines_epidemiologia/pdfs/BEPANUAL_2010.pdf.

MSAL - Ministerio de Salud de la Nación Argentina. 2014. Programa Nacional de Chagas. Available from: prensa.argentina. ar/2014/08/27/52387-salud-aprobo-un-aumento-del-accesoetareo-al-tratamiento-por-mal-de-chagas.php.

Palacios X, Belli A, Espino A 2000. Detection of antibodies against Trypanosoma cruzi in Somoto, Nicaragua, using indirect ELISA and IFI on blood samples on filter paper. Rev Panam Salud Publica 8: 411-417.

Schmunis GA 2007. Epidemiology of Chagas disease in non-endemic countries: the role of international migration. Mem Inst Oswaldo Cruz 102 (Suppl. I): 75-85.

Segura E, Sosa-Estani S, Esquivel M, Gómez A, Salomon O 1999. Control of the transmission of Trypanosoma cruzi in Argentina. Medicina (Buenos Aires) 59 (Suppl. 2): 91-96.

Spillmann C, Burrone S, Coto H 2013. Análisis de la situación epidemiológica de la enfermedad de Chagas en Argentina: avances en el control, 2012. Rev Argent Salud Pública 4: 40-44.

Zicker F, Smith P, Luquetti A, Oliveira O 1990. Mass screening for Trypanosoma cruzi infections using the immunofluorescence, ELISA and haemagglutination test on serum samples and on blood eluates from filter-paper. Bull World Health Organ 68: 465-471. 